\title{
Aorto-coronary saphenous vein bypass grafting in a patient with a single coronary artery arising from the right aortic sinus
}

\author{
S MILO, Y KISHON, D GOOR, AND H N NEUFELD \\ From the Department of Cardiothoracic Surgery and the Heart Institute, the Chaim Sheba Medical Center, \\ Tel-Hashomer, Sackler School of Medicine, University of Tel-Aviv, Israel
}

ABSTRACT A patient who presented with severe angina was found to have an ectopic origin of the entire left coronary system, the left main coronary artery arising from the proximal third of the right coronary artery. Atherosclerotic obstructive lesions were present in the right coronary artery, the left anterior descending artery, and the obtuse marginal branch of the left circumflex coronary artery. The three obstructed vessels were bypassed, using autologous saphenous veins. The patient continues to do well 24 months after his operation. We believe that coronary artery bypass should be carried out in symptomatic patients with abnormal coronary anatomy and atherosclerotic disease.

Anatomical abnormalities of the coronary arteries are an infrequent but important form of congenital cardiovascular malformation. The single coronary artery with its different forms of distribution does not usually cause symptoms and is of little or no functional significance, provided there is adequate perfusion of the myocardium. ${ }^{12}$ In later life, however, patients with a solitary origin of their coronary arteries are more vulnerable to atherosclerotic obstructive lesions than those who have another source of blood flow into their coronary system. ${ }^{34} \mathrm{We}$ describe a patient in whom the entire left coronary system arose from the right coronary artery (RCA) and who required coronary bypass surgery because of severe obstructive disease.

\section{Case report}

A 58-year-old Caucasian man presented with typical anginal pain radiating to both arms. Three weeks later he was admitted to a coronary care unit for suspected myocardial infarction. He was discharged two weeks later on treatment with nitroglycerin and a betaadrenergic blocking agent. The pain persisted and he was referred to the Heart Institute in

Address for reprint requests: $\operatorname{Dr} Y$ Kishon, Heart Institute, Chaim Sheba Medical Center, Sackler School of Medicine, Tel-Hashomer, Israel. our hospital.

On admission his physical examination was normal. The electrocardiogram was normal and showed no evidence of previous myocardial infarction. The chest radiograph was normal. The patient had a positive exercise test. There was chest pain and $3 \mathrm{~mm}$ depression of the ST segment in leads III and aVF at the fifth minute of $300 \mathrm{~kg}$ per minute effort with heart rate $60 \%$ of the predicted maximal rate. Selective coronary angiography revealed a solitary origin of the entire coronary system, which arose from the right sinus of Valsalva (fig 1). The left main coronary artery (LMCA) arose from a single common trunk and ran anterior to the pulmonary artery along the right ventricular outflow tract, where it bifurcated into a left anterior descending artery (LAD) and circumflex artery (LCxA), running a normal course and having the usual branches.

The right coronary artery (RCA) was the vessel supplying the posterior descending coronary artery and the artery to the atrioventricular node. It had a $50 \%$ obstruction in its middle third with distal nonobstructive atheroma. Obstructive lesions of $70-80 \%$ were located in the LAD, its first diagonal branch and the marginal branch of the LCxA.

At operation saphenous vein grafts were inserted from the aorta into the LAD, diagonal, and circumflex arteries. The patient made an uneventful recovery and on discharge his 

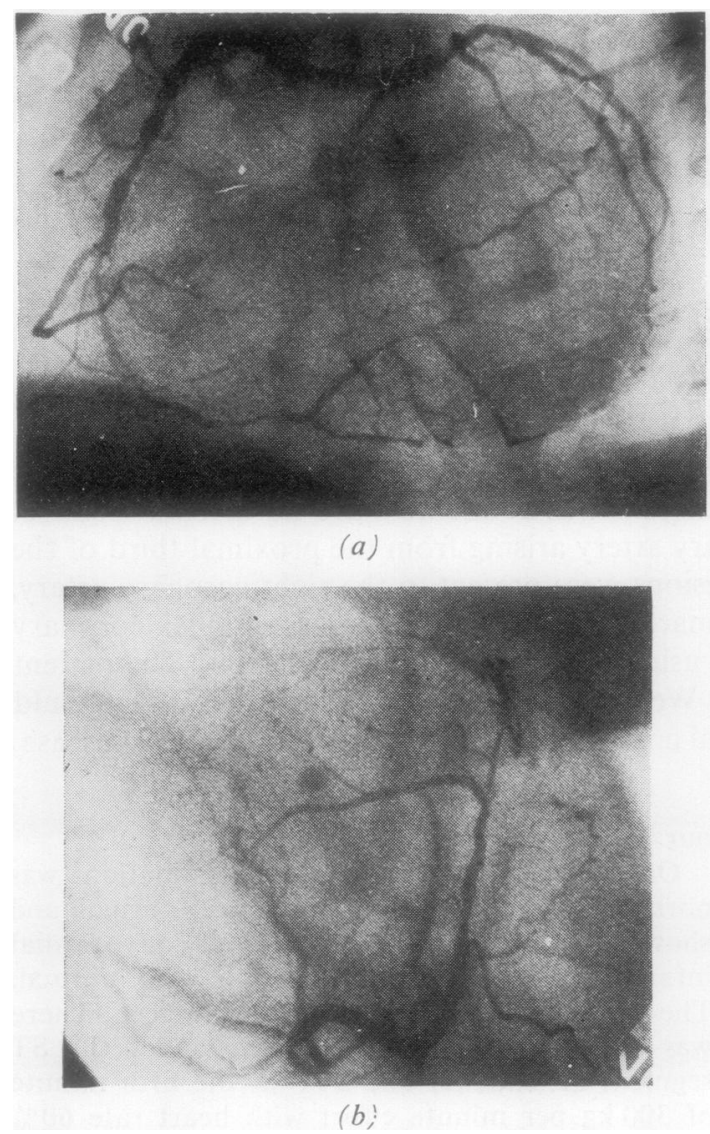

Fig 1 Coronary angiogram of a patient with single coronary artery-(a) $45^{\circ}$ left anterior oblique, (b) $30^{\circ}$ right anterior oblique.

electrocardiogram was normal. He continues to do well 24 months after his operation.

\section{Discussion}

The single coronary artery is not an unusual variation. It occurs when the proximal coronary artery, for unknown reasons, fails to form appropriately. The lesion is found in association with other cardiovascular defects as well as in otherwise normal hearts. These anomalies can probably be ascribed to a common developmental failure of the proximal portion of one coronary artery. This is caused by the existence of large anastomoses from the other coronary artery. ${ }^{5}$ However, a LMCA originating from the RCA, crossing anterior to the right ventricular outflow tract and subsequently dividing into its circumflex and anterior descending branches (fig 2) is rare.

A review of 36 patients with congenital? anomalies of the coronary arteries ${ }^{5}$ included two $\overline{\bar{c}}$ cases similar to ours-one in a 6-month-old $\overrightarrow{\widetilde{\sigma}}_{\vec{\sigma}}$ baby girl and one in an 11-day-old boy. A more ${ }^{\circ}$ recent comprehensive study ${ }^{6}$ includes no suchô cases. In a study by Kimbiris et al 45 of $7000 \vec{\circ}$
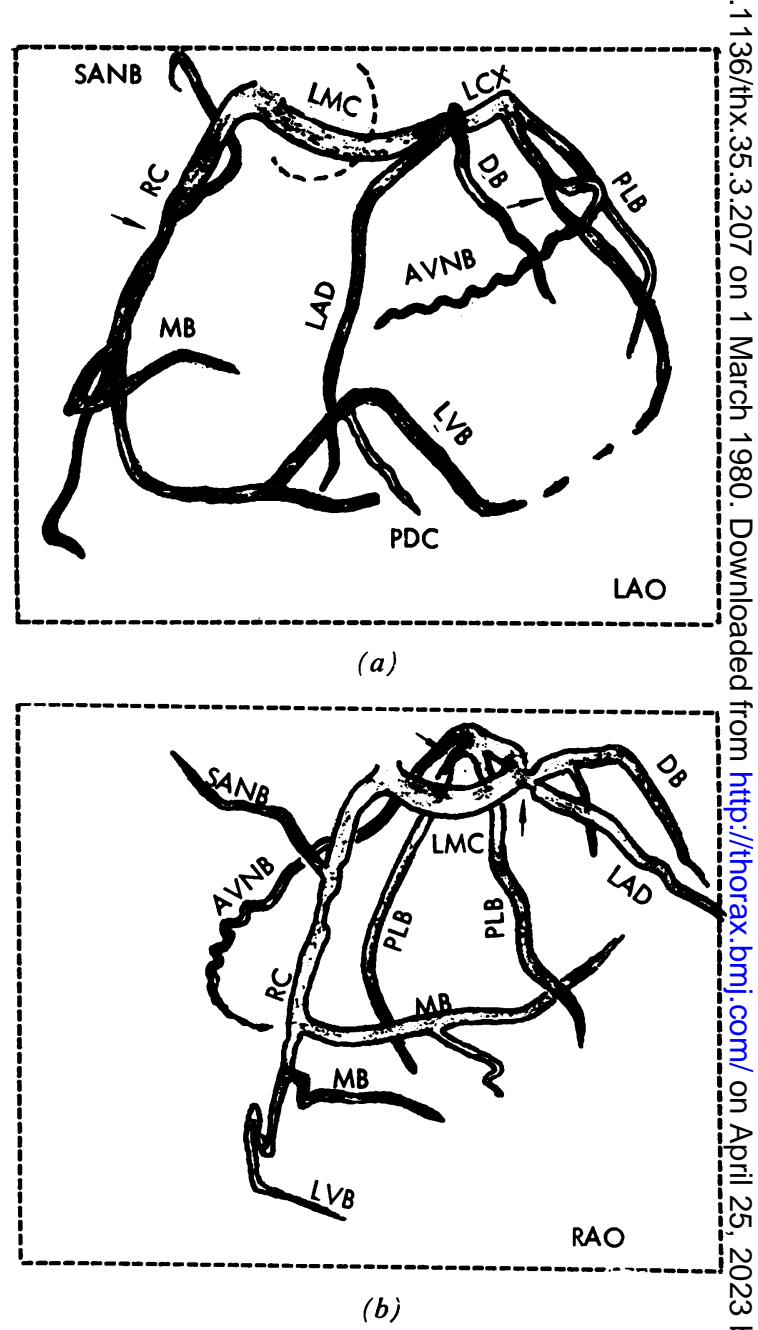

Fig 2 Composite tracing of the arterial distribution in the same patient-(a) and (b) as in fig 1. The single common trunk of the coronary system originates from the right aortic sinus. $L M C=$ left main coronary artery, $R C=$ right coronary artery, $L A D=$ left anterior descending coronary artery, $L C X=$ left circumflex artery, $D B=$ diagonal branch $M B=$ marginal branch, $S A N B=$ branch to $S A$ node, $A V N B=$ branch to $A V$ node, $P D C=$ posterior descending coronary artery, PLB=posterolateral branch, and $L V B=$ branch to $L V$. 
successive coronary angiograms revealed the existence of an anomalous aortic origin of one or more coronary arteries. In only four patients $(0.6 \%)$ did both coronary arteries arise from the right sinus of Valsalva; in only one case $(0.15 \%)$ did both arteries originate from a single ostium as in our patient. We were unable to find similar published cases where the diagnosis was made angiographically, and surgical correction by saphenous vein graft bypass was successfully performed. Our patient had no other anomalies. A similar anomaly is found in the tetralogy of Fallot in about $1.7 \%$ of the patients undergoing total correction. ${ }^{8}$ The precise identification of the coronary anatomy is of major significance in these cases since the LAD may cross the line of ventriculotomy. The coronary arteries may show an abnormal pattern in various congenital malformations such as in large ventricular septal defects, ${ }^{9}$ and in complete transposition of the great vessels. ${ }^{610}$

The single coronary artery can originate from the right or left sinus of Valsalva, and the initial course of the vessel could be posterior to the aorta, between the aorta and the pulmonary artery, or anterior to the pulmonary artery, as in our patient. Even with nonobstructive coronary arteries, patients with single coronary artery may develop angina, acute myocardial infarction or sudden death. This last complication occurred in patients with an abnormal left main artery between the aorta and pulmonary artery. ${ }^{7}$

The single coronary artery is just as prone, if not more so, to atheromatous changes as are the two normal coronary arteries. ${ }^{34}$ However, the consequences of atherosclerotic disease in this "single" artery may be far more serious, since collaterals from a second coronary artery are not present. Sudden occlusion of the proximal portion of a single coronary artery carries a high incidence of sudden death. ${ }^{11} 13$

Myocardial blood flow was adequate in our patient until late in adult life. The development of obstructive lesions in addition to the ab- normal coronary distribution, contributed to the severity of his condition. We believe that coronary artery bypass should be performed in symptomatic patients with abnormal coronary anatomy and atherosclerotic disease.

\section{References}

1 Stapley LA, Edwards JE. Single coronary artery. Arch Pathol 1951; 52:470-2.

2 Sandison AT. Congenital absence of the right coronary artery with report of a case in a coal miner with gross hypertrophy of the right ventricle. Glasgow Med J 1955; 36:343-47.

3 Roberts JT, Loube SD. Congenital single coronary artery in man. Am Heart $J$ 1947; 34: 188-208.

4 Alexander RW, Griffith GC. Anomalies of the coronary arteries and their clinical significance. Circulation 1956; 14:800-5.

5 Ogden JA. Congenital variations of the coronary arteries. Thesis, Yale University School of Medicine, 1968.

6 Vlodaver Z, Neufeld HN, Edwards JE. Coronary arterial variations in the normal heart and in congenital heart disease. New York: Academic Press, 1975.

7 Kimbiris D, Iskandrian AS, Segal BL, Bemis CE. Anomalous aortic origin of coronary arteries. Circulation 1978; 58:606-15.

8 Berry BE, McGoon DC. Total correction for tetralogy of Fallot with anomalous coronary artery. Surgery 1973; 74:894-8.

9 Lardani H, Sheldon WC. Ectopic origin of the left anterior descending coronary artery from the right coronary sinus. Chest 1976; 69:548-9.

10 Rowlatt UF. Coronary artery distribution in complete transposition. $J A M A$ 1962; 179:269-78.

11 Blake HA, Manion WC, Mattingly TW, Baroldi G. Coronary artery anomalies. Circulation 1964; 30:927-40.

12 Smith JC. Review of single coronary artery with report of two cases. Circulation 1950; 1:1168-75.

13 Spring DA, Thomsen JH. Severe atherosclerosis in the "single coronary artery". Am J Cardiol $1973 ; 31: 662-5$. 